\title{
Transfer Baskı Tekniğinin Basım Yayın Teknolojileri Programlarında Okutulan Baskı Teknikleri Dersine Entegrasyonu
}

\section{Engin Ŭgur ${ }^{1} *$}

Gelis tarihi: 23.02.2019

Kabul tarihi: 13.03.2019

\section{Atıf bilgisi:}

Uluslararası Bilimsel Araștırmalar Dergisi (IBAD)

Cilt: $4 \quad$ Sayı: 2

Sayfa: 253-266 Yll: 2019

Dönem: Yaz

This article was checked by Turnitin. Similarity Index 10\%

1İstanbul Üniversitesi Cerrahpaşa, Turkiye, engines@istanbul.edu.tr, ORCID ID 0000-0001-7831-5449

* Sorumlu yazar
$\ddot{O} \mathrm{z}$

Tekstil sektöründe kumaşların desenlendirilmesi için geliştirilen transfer baskı teknolojileri, sahip olduğu baskı özelliğinden dolayı her geçen gün kullanım alanını genişletmektedir. Bugün tekstil ürünleri dışında reklamcılık ve kişisel matbaacılık ürünleri ve çok farklı materyale baskı yapmak için tercih edilmektedir. Özellikle matbaacılık ve reklamcılık sektöründe konvansiyonel baskı teknolojilerinin yanında hızla yerini almaya başlamıştır. Ortaya çıkan bu durum basım ve reklam sektöründe bu teknolojileri kullanacak kalifiye eleman ihtiyacını da beraberinde getirmektedir.

Meslek liselerinin Matbaa Bölümleri ve Basım Yayın Teknolojileri ön lisans programları; basım, yayın ve reklamcılık sektörlerine yönelik ara eleman yetiștiren eğitim kurumlarıdır. Bu eğitim kurumlarının birinci önceliği sektörün değişen ve gelişen yapısına cevap verebilmeleridir. $\mathrm{Bu}$ amaçla ilgili eğitim kurumları transfer baskı tekniğinin öğretilmesine yönelik müfredat ve teknik altyapıyı oluşturmaları gerekmektedir. Transfer baskı tekniğine yönelik kaynak kitap ve ders notunun olmaması da eğitim açısından bir eksiklik oluşturmaktadır. Öğretim elemanları ve öğretmenler tarafından kitap ve ders notları oluşturulması da gerekecektir.

Makale iki aşamadan oluşmaktadır. Birinci aşamada; hızla yaygınlık kazanan transfer baskı tekniği, teknoloji ve üretim süreçleri ile tanımlanmaya çalışılmıştır. İkinci aşamada; bu teknik bilgiler çerçevesinde ön lisans programlarındaki ilgili dersin (baskı teknikleri ya da yöntemleri) müfredatına uyarlanması yapılmaya çalıșılmıştır.

Anahtar Kelimeler: Transfer baskı, basım yayın, reklamcılık, eğitim. 


\section{Integration of Transfer Printing Technique to Printmaking Techniques Taught in Print Publishing Technology Programs}

Engin Uğur ${ }^{1 *}$

First received: 23.03 .2019

Accepted: 13.03.2019

\section{Citation:}

Journal of the International

Scientific Research (IBAD)

Volume: $4 \quad$ Issue: 2

Pages: 253-266 Year: 2019

Session: Summer

This article was checked by Turnitin. Similarity Index 10\%

\footnotetext{
${ }^{1}$ Istanbul University Cerrahpaşa, Turkey, engines@istanbul.edu.tr,

ORCID ID 0000-0001-7831-5449
}

* Corresponding Author

\begin{abstract}
Developed for patterning fabrics in the textile sector, transfer printing technologies expand their usage area every day due to their printing possibilities. Today, apart from textile products, advertising and personal printing products are preferred for printing a wide variety of materials. Especially in the printing and advertising sector, it has started to take its place rapidly alongside conventional printing technologies. This emerging situation brings with it the need for qualified personnel to use these technologies in the printing and advertising sector.

Printing and broadcasting technologies associate degree programs of vocational high schools are educational institutions that produce intermediate staff for the printing and Broadcasting and Advertising sectors. The primary priority of these educational institutions is that they are able to respond to the changing and developing structure of the sector. For this purpose, relevant educational institutions need to establish a platform and technical infrastructure for teaching transfer printing techniques. Lack of textbooks and course notes for transfer printing technique is a lack of Education. It will also be necessary to create books and lecture notes by the instructors and teachers.

The article consists of two phases. In the first phase, transfer printing technique, technology and production processes, which became widespread rapidly, were tried to be defined. In the second stage, it was tried to adapt the related course (printing techniques or methods) in the associate degree programs within the framework of this technical information to the curriculum.
\end{abstract}

Keywords: Transfer printing, print publishing, advertising, education 


\section{GíRIŞ}

Basım endüstrisi, çok geniş ürün yelpazesini üreten üretim teknikleri ve teknolojilerine sahiptir. Bu geniş üretim yapısının Basım ve Yayın Teknolojileri Programlarında öğretilmesi, zor bir durum olarak karşımıza çıkmaktadır. Farklı baskı teknikleri, sahip oldukları teknolojiler, malzemeler, ürünler ve üretim süreçleri ile her biri kendi içinde mesleki uzmanlık alanı oluşturmaktadır. Bu geniş yapıdan dolayı, günümüzün yaygın kullanılan teknolojilerine daha kapsamlı yer vermesi gerekmektedir. Transfer baskı tekniği de bu öncelikler içinde yer alacak bir baskı tekniğidir. Transfer bask1 tekniği, okulların atölyelerinde uygulama yapabilmek için büyük yatırımlar yapmaya gerek olmayan bir özelliğe sahiptir. Şu an Milli Eğitim Bakanlığı Özel Öğretim Müdürlüğüne bağlı okulların baskı atölyelerinin hemen hemen tamamında transfer baskı imkânları oluşturulmuş ve aktif bir şekilde kullanılmaktadır. Basım ve Yayın Teknolojileri Programlarının Baskı Yöntemleri (Baskı Teknikleri) dersi içinde teorik olarak ögretilmesi, atölye dersleri içinde de imkânlar dâhilinde çok faklı ürünlerin üzerine baskı yaptırılması pratik beceri kazanılmasına katkı sağlayacaktır. Transfer baskı uygulamalarında öğrencilere kendilerine ait ürünler yaptırılması eğitim motivasyonu açısından da faydalı olacaktır.

\section{TRANSFER BASKI TEKNOLOJISI}

\subsection{TRANSFER BASKI TARIHÇESI}

Termoplastik eriyen transfer baskı; transfere uyumlu bir kâğıt üzerine ofset veya serigrafi (ipek baskı) teknikleri ile basılan deseni 1sı, basınç uygulayarak kâğıdı ters çevirip materyal yüzeyine transfer etme işlemidir. Baskı esnasında kâğıt, kumaş ile birleşir ve kâğıt üzerindeki boyarmadde partikülleri 1sı ile yumuşayarak materyale yapışır. Transfer sonrası desen, materyal yüzeyine aktarılır ve taşıyıcı kağıt yüzeyden ayrılır. Bu metot 1940'ların sonlarında İtalya'da geliştirilen, transfer baskı diyebileceğimiz ticari olarak ilk başarılı adımdır (Ratte, 2003, s. 58). Bu yöntemle tişörtlere, promosyon, vb. ürünlere baskı yapılmaya başlanmıştır. Süblime transfer baskının 1952 başlarında ICI firması tarafından patenti alınmıştır. Transfer baskının ticari olarak uygun olmadığı düşünülmüş ve bundan dolayı sistemin üzerine düşülmemiştir. Böylece patent hakları geçersiz sayılmıştır. 1960 yılında Noel Deplasse tarafından tekrar denemelerine başlamıştır. 1965 yılında Fransa'da yeniden transfer süreci ile eşanlamlı Sublistatic olarak adlandırmıştır. Böylelikle Noel Deplasse Societe, Sublistatic S.A. firması kurulmuştur. Sublistatic baskı olarak da bilinen transfer baski; kuru, sıcak baskıdır. 1953'de İtalya'nın Milano kentinde Stampa Tessutti Artistici tarafindan Star baskı tekniği tanıtılmışıır. Bu yöntem günümüzdeki transfer baskıya doğrudan ve gerçek öncü metottur. Kâğıt fotogravür tekniği ile basılmış ve genelde doğal ipeğe ya da iyi kalitede pamuğa ya da sentetik elyafa transfer edilmiştir (Storey, 1974, s. 154). Termotransfer baskı kâğıtları, diğer bir adıyla eriyen parça transfer baskıdır. Yarı ıslak transfer baskı yönteminde desenlenen kâğıt ters çevrilerek nemlendirilmiş tekstil yüzeyine aktarılır. Tasarımcı desen tasarlarken bu yöntemin ters baskı olduğunu göz önüne almalıdır. Islak transferde, kâğıtta desen üretimi için baskı boyar maddesi ile su bazlı mürekkepler birleştirilir. Bu metot ilk olarak 1960'lı yılların başlarında Dlyon tarafindan üretilmiştir (Wells, 1997, s. 109). Özellikle 1980'lerden sonra düşük maliyetli ve kaliteli transfer mürekkep ve yazıcı üretimi tüm dünyada transfer baskının yaygınlık kazanmasını sağlamıştır. Günümüzde sadece tekstil ürünlerine değil reklam ve hediyelik ürün üretiminde de geniş bir kullanım alanına sahiptir.

\subsection{TRANSFER BASKI TEKNIĞI}

Transfer baskı, katı halde bulunan süblimasyon mürekkebinin sıcak presleme işlemi sonucunda direkt gaz haline geçerek basılacak materyalin üzerindeki veya içeriğindeki polimer yüzeye tutunduğu bir baskı tekniğidir. Transfer baskıda önce bilgisayardaki tasarım, transfer mürekkebin kullanıldığı yazıcılar (printer) ile transfer kağıdına aktarılır. Daha sonra transfer kağıdındaki görüntü materyalin üzerine sıcak pres yardımı ile transfer edilerek baskı işlemi tamamlanır ("Tekstil Üzerine Süblimasyon Baskılarda Transfer Bask1 mı Dispers Baskı mı?", 2015). Bundan dolayı bu bask1 tekniğine transfer baskı denilmektedir. Transfer baskı tekniği diğer baskı teknikleri gibi direkt baskı imkânına sahip değildir. $\mathrm{Bu}$ nedenle endirekt baskı olarak da tanımlanabilir. Transfer baskının gerçekleştirilmesinde üç özel unsura ihtiyaç vardır: 
a) Özel transfer kâğıd1,

b) Özel transfer mürekkebi (süblimasyon),

c) Termal presleme işlemi

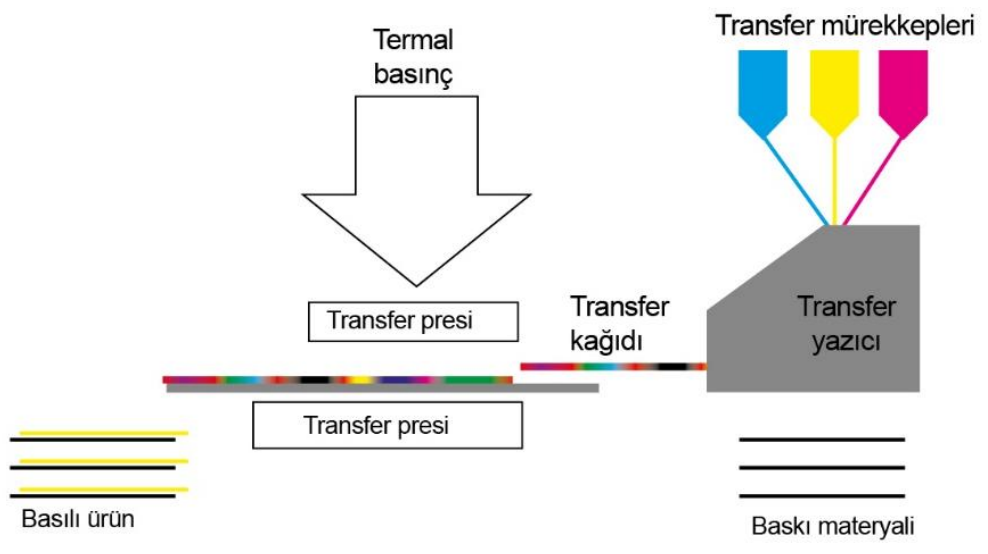

Şekil 1. Transfer bask1 sistematiği (Sublimation, 2018).

Yüzey yapısı transfer mürekkebini kabul edecek özelliğe sahip tekstil, metal, cam, seramik ve plastikten üretilmiş düz, eğimli ve üç boyutlu her türlü ürüne baskı yapılabilir. Transfer baskının tercih edildiği ürünler; seramik kupa, isimlik, magnet, madalya, şapka, çanta, tişört, telefon kılıfı, puzzle, yastık kılıfi, vb. dir.

\subsection{TRANSFER BASKI ISSTEMINDE KULLANILAN TEKNOLOJILER VE MALZEMELER}

\subsubsection{Transfer Baskı Yazıcıları (Süblimasyon Yazıcılar)}

Transfer baskı yazıcıları, diğer ink-jet yazıcılar ve dijital yazıcıların benzeri cihazlardır. Diğer ink-jet yazıcılardan farkı, süblimasyon mürekkebi ile çalışıyor olmalarıdır. Transfer yazıcılar, bilgisayardan gelen görüntü sinyallerini RIP yardımı ile yazıcı komutlarına dönüştürerek yazdırma işlemini gerçekleştirir. Transfer yazıcıların masaüstünde A4 kağıdına yazdırma imkanı sağlayan küçük modellerinin yanında büyük ebatlarda özelikle bobin kağıda çalışan türleri de vardır.

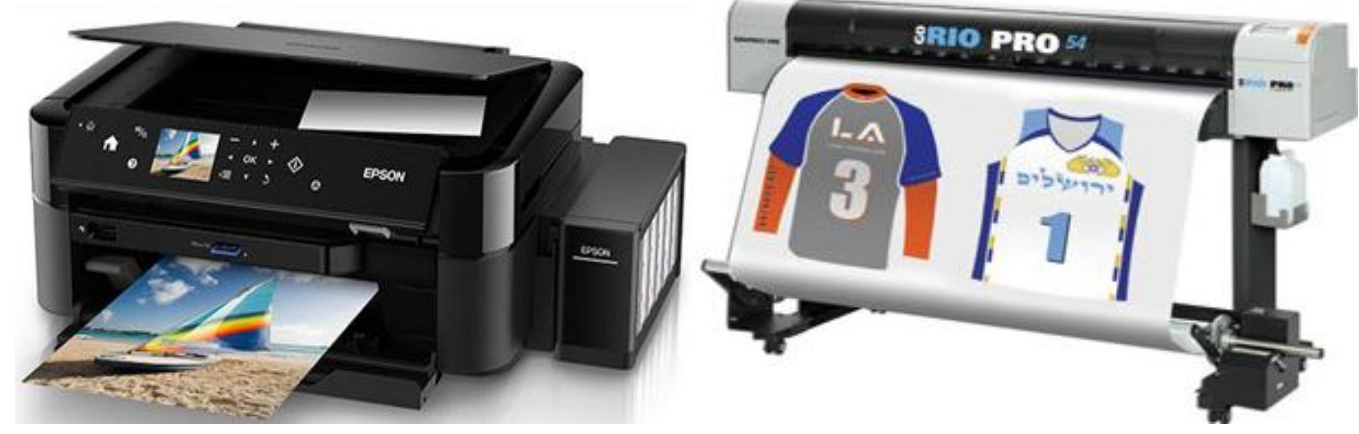

Şekil 2. Farklı ebat ve özelliklerde transfer baskı yazıcıları

(Epson L-Series Printers, 2018; Graphics One: GO RIO PRO 5454 inç Süblimasyon Baskı Yazıcısı, 2011).

\subsubsection{Transfer Baskı Mürekkepleri}

Transfer baskı işleminde kullanılan mürekkepler süblime özelliğe sahiptir. Bundan dolay1 süblimasyon mürekkepler olarak da adlandırılmaktadır. Transfer mürekkebi içinde süblimleşme özelliğe sahip renkli katı mikro parçacıklar yer alır. Süblimleşme katı parçacıklar ısıtılınca, ara bir hal olan sıvı hâle geçmeden doğrudan gaz hâle geçmesine denir ve endotermik faz değişimidir. 


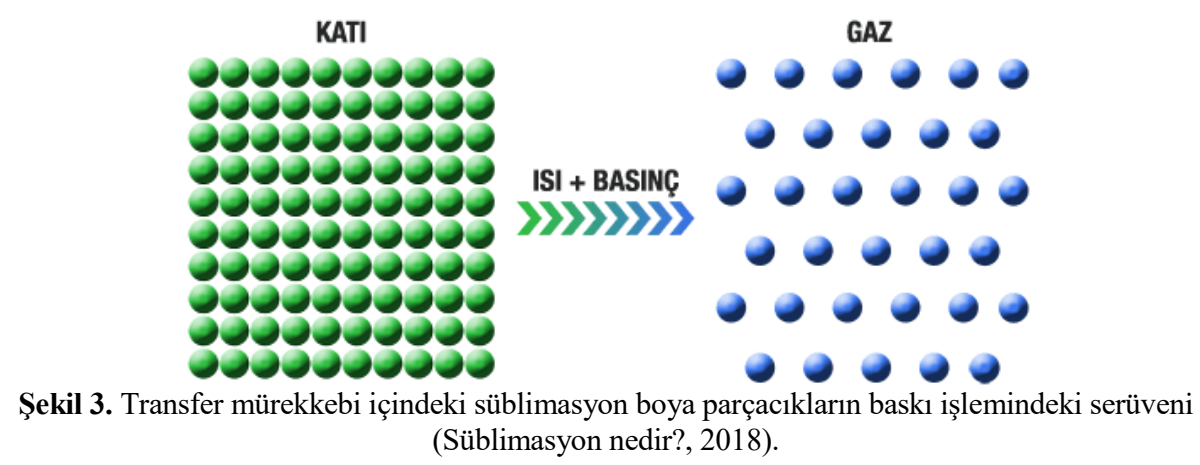

Transfer yazıcısı yardımı ile transfer kağıdında görüntüyü oluşturan bu renkli mikro parçacıklar, sıcaklık altında preslendiğinde transfer kağıdı üzerinde bulunan katı mikro parçacıklar gaz haline geçer. Baskı yapılan materyal transfer baskı kâğıdı üzerindeki mürekkebi içerisine hapseder, böylelikle baskı gerçekleşmiş olur (a.g.i.s., 2018). Eğer ortamda polyester molekülleri bulunuyorsa gaz haline geçen mürekkep polyester moleküllerini boyar. Baskı yapılacak yüzey polyester içermiyorsa gaz haline geçen mürekkep havaya karışır. Buradan da anlaşılacağı üzere süblimasyon transfer yöntemiyle baskı yapılacak ürünlerin üzerinde polyester, polyamid molekülleri mutlaka olmalıdır. Aksi halde transfer sağlanamaz. ${ }^{6}$ Süblimasyon mürekkeplerinde üç tür vardır:

a. Su bazlı mürekkepler,

b. Solvent bazlı mürekkepler,

c. Yağ bazlı mürekkepler.

Her üç tipteki mürekkebin de transfer uygulaması aynıdır.

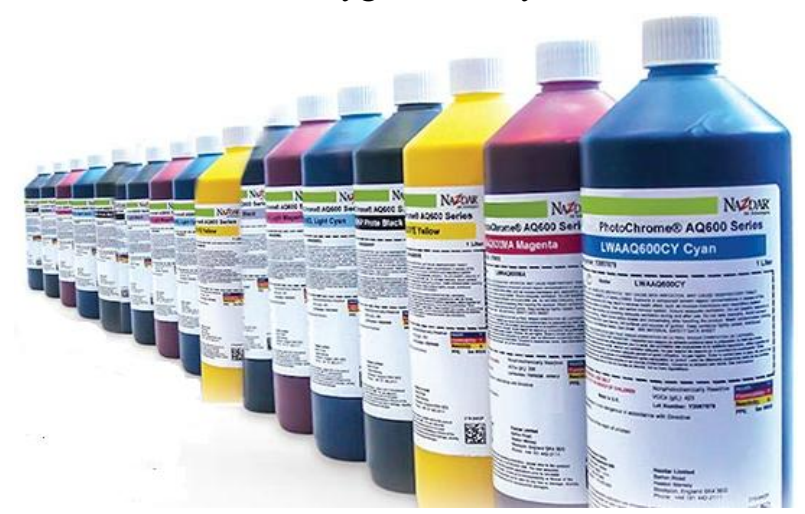

Sekil 4. Faklı renklerde satıșa sunulmuș transfer mürekkepleri

(“Nazdar'dan Yeni Süblimasyon Mürekkepleri: Daha az mürekkep, daha yüksek baskı yoğunluğu”, 2018).

\subsubsection{Transfer Baskı Kâğıtları}

Transfer kâğıdı 1Sı ve basınç altında mürekkebi bırakan polimer kaplı bir kâğıttır. Transfer kâğıdı, mürekkebi yüzeyinin her alanında eşit şekilde tutunmasını sağlayacak yüzey yapısına sahip olmalıdır. $\mathrm{Bu}$ nedenle kâğıtların bir yüzü transfer mürekkebini tutacak özelliğe sahip maddeyle kaplanır. Transfer kâğıtları yüksek sıcaklığa dayanaklıdırlar. Yazdırma işlemi sonucunda oluşan film katmanın düzgünlügü baskı kalitesini belirleyen önemli bir kriterdir. Transfer kâğıdının ikinci önemli özelliği transfer presinde sıcaklık ve basınç altında yüzeyindeki tüm mürekkebi salıvererek materyalin üzerinde en fazla miktarda mürekkep katmanı oluşumuna yardımcı olmasıdır. Kâğıt üzerindeki mürekkep ne kadar çok transfer olursa, kâğıt üzerinde de çok az mürekkep kalır. Bu kâğıtlar, ürüne maksimum mürekkebin basılmasını sağlar. Baskı kalitesi açısından mürekkebin ürün üzerinde fazla olması, renklerin daha canlı görünmesini sağlar. Ayrıca küçük detayların kaybolmasını engeller. Transfer kâğıt üreticileri farklı özelliklerde kâğıtlar ürettikleri için her transfer kâğıdı, her transfer mürekkebi ile uyumlu sonuçlar vermeyebilir. Bu nedenle testler yapılarak satın alma gerçekleştirilmelidir. 


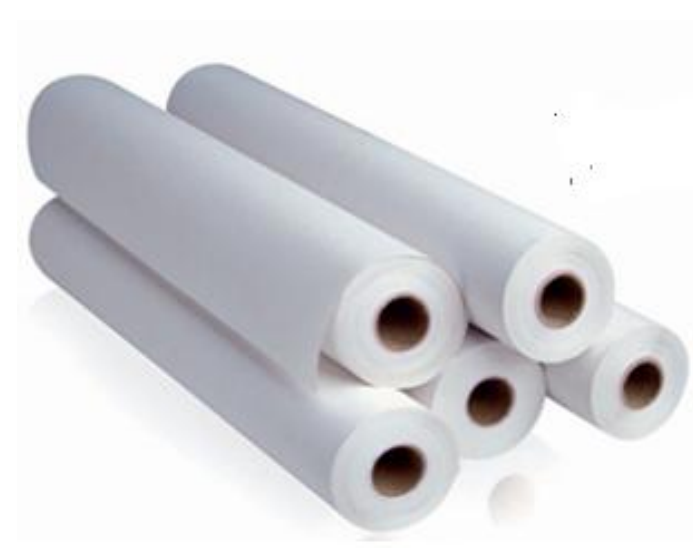

Şekil 5. Bobin transfer kağıdı

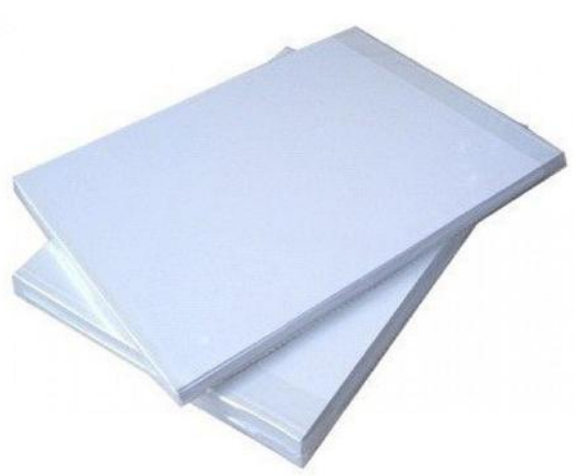

Şekil 6. Tabaka transfer kağıdı

\subsubsection{Transfer Baskı Presleri}

Transfer baskı presi, transfer kâğıdındaki süblimasyon mürekkepli görüntüyü baskı materyaline sıcaklık ve basınç uygulayarak aktarılmasını sağlayan cihazdır. Transfer presleri yapısal olarak üç ana gruba ayrilmaktadır;

a) Ürünün özelliklerine göre sıcaklık ayarının yapılabildiği fakat insan gücüyle çalışan manuel transfer presleri

b) Sıcaklığın ve presleme süresinin ayarlanabildiği ve preslemenin pnömatik (hava kompresörü basınc1) olarak insan gücüne gerek kalmadan çalışan yarı otomatik transfer presleri

c) Bobin ürüne transfer yapabilen otomatik rotasyon (metraj) transfer presleri

Ayrıca transfer yapılacak üç boyutlu ürünün şekline göre dairesel, silindirik, eğik transfer tablalarına sahip modeller de vardır. İşletmenin iş kapasitesine ve ekonomik gücüne uygun teknoloji seçimi yapılmalıdır. Satın alınıp üretim kapasitesinde yetersiz kalan, bunun yanında baskı kalitesi olarak alt değerlerde sonuçlar veren teknolojiler kısa sürede ya bir kenara atılmakta ya da ikinci el olarak satılmaya çalışılmaktadır. Çünkü insan faktörünün olduğu manuel teknolojilerin üretim kapasitesi ve bask1 sonuçları ile yarı veya tam otomatik cihazların üretim kapasitesi ve baskı kalitesi açısından büyük farkların olduğu kaçınılmaz bir durumdur. Son yıllarda ülkemizde yabancı teknolojilerin yanında çok ileri düzeyde üretilmiş yerli teknolojiler de yaygın olarak kullanılmaktadır.

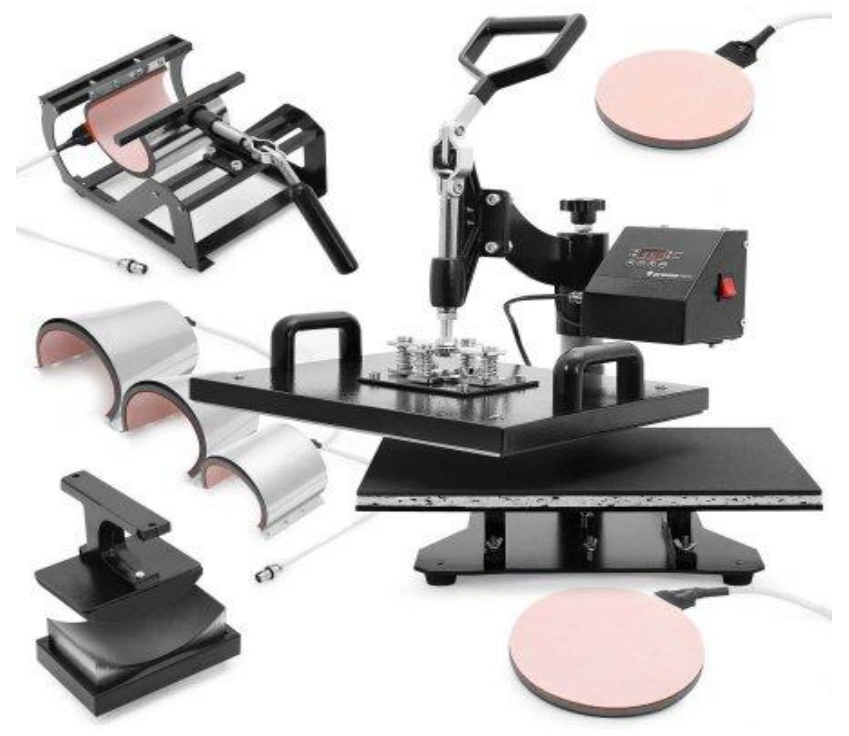

Şekil 7. Manuel transfer presi ve farklı ürünlere baskı yapabilmeyi sağlayan aparatları

(Promo Heat Professional 8 in 1 Multifunction Sublimation Heat Press Machine - Model PRO-8800X, 2018). 

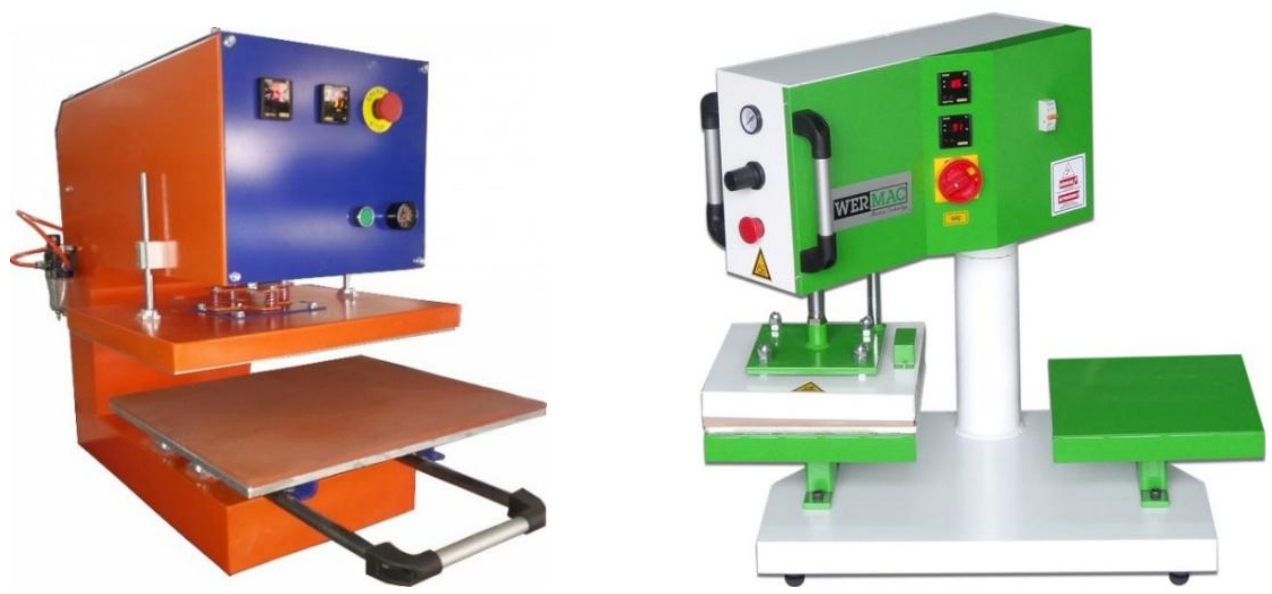

Şekil 8. Faklı tip pnömatik transfer presleri (38x38 Pnömatik Transfer Baskı Presi, 2018; Wermac Mod - H506, 2018).

\subsection{TRANSFER BASKI ISŞLEM AŞAMALARI}

Konvansiyonel baskı teknikleri (ofset bask1, flekso baskı, serigrafi baskı, tifdruk baskı) üç aşamadan meydana gelir; 1. Bask1 hazırlı (grafik tasarım-kalıp hazırlama), 2. Baskı işlemi, 3. Baskı sonrası işlemler (kurutma, kesme, katlama, yapıştırma, dikme, vb.). Transfer baskı tekniği de üç aşamadan meydana gelmektedir fakat işlem aşamaları tamamen aynı değildir; 1. Baskı hazırlık (grafik tasarımtransfer kağıdına yazdırma), 2. Termal (sıcak) presleme işlemi, 3. Baskı sonrası işlemler (kesme, katlama, yapıştırma, dikme, vb.). Transfer işleminden sonra ürün direkt kullanıma hazır olabilir ya da kesme, katlama, yapıştırma, dikme, vb. işlemlerden geçirilerek son halini alması sağlanır.

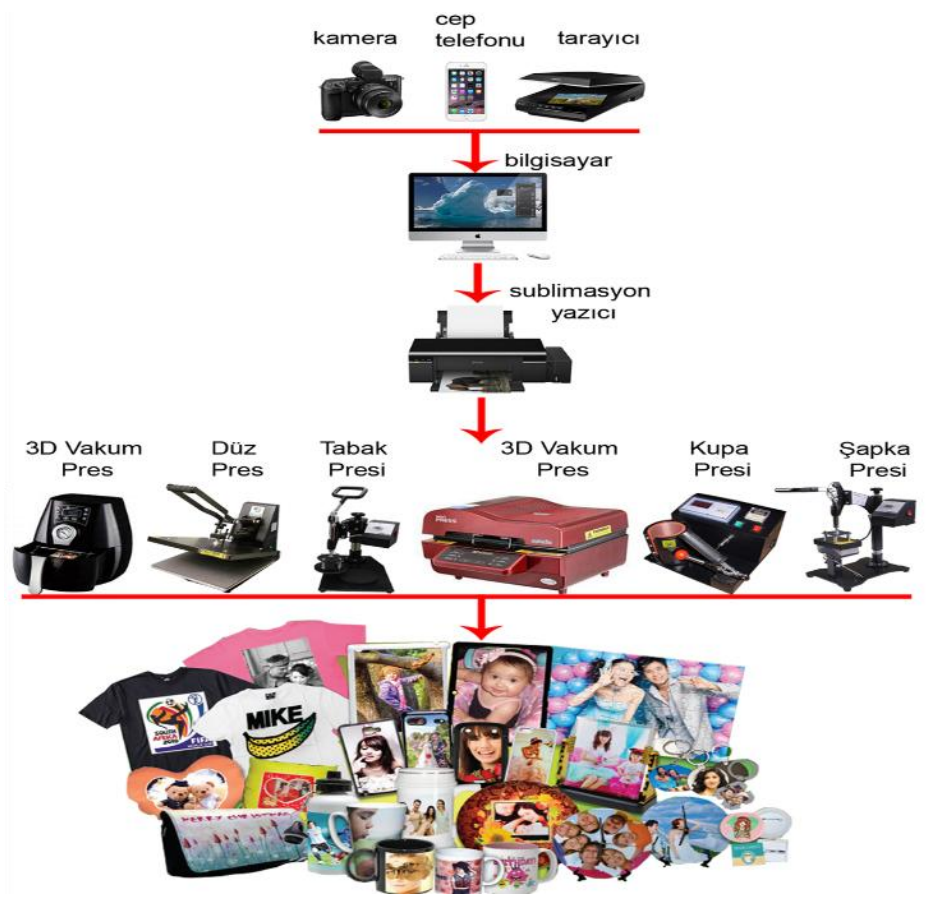

Şekil 9. Transfer baskı prosesi infografik (Sublimasyon nedir? Sublimasyon Baskı Nasıl Yapılır?, 2018).

\subsubsection{Transfer Baskı Hazırlık İşlemi}

\subsubsection{Grafik Tasarım}

Diğer baskı tekniklerinde olduğu gibi transfer baskı işleminde de önce basılması istenen görselin grafik tasarım çalışması yapılmalıdır. Ürünün özelliğine göre renkli işlerde yarımton alanların elde edilmesini 
sağlayan tram türü ve değerleri doğru bir şekilde hazırlanmalıdır. Ayrıca çok ince detayların olduğu görsellerde basılacak materyal kaba yüzey yapısına sahip ise tam basılamama durumuna neden olacaktır. Bu nedenle ürünün özelliğini bilerek tasarımı yapmak gerekmektedir.

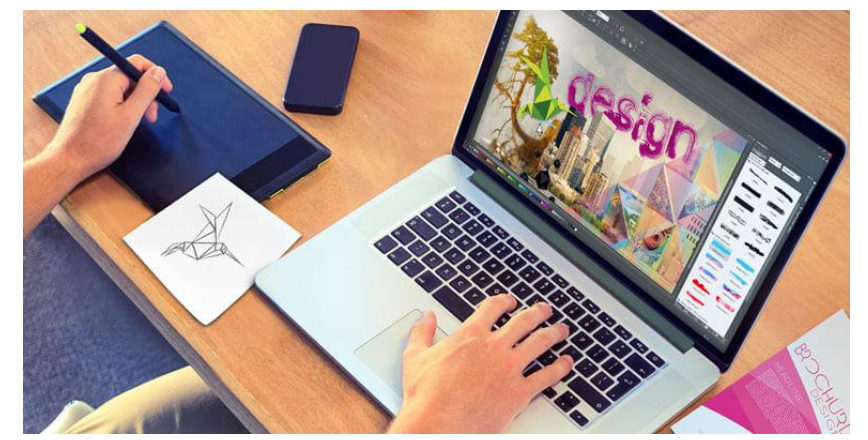

Şekil 10. Basılacak işin özelliklerine göre grafik tasarımı yapılır (www.magix.com)

\subsubsection{Transfer Yazıcıdan Çıktının Alınması}

Bilgisayarda hazırlanan çalışma özel transfer mürekkeplerin kullanıldığı transfer yazıcıya gönderilerek transfer kâğıdına çıktısı alınır. Yazıcıda bulunan RIP bilgisayardan gelen 0/1 komutlarını yazıcının satır satır yazma komutalarına dönüştürülmesini sağlamaktadır.

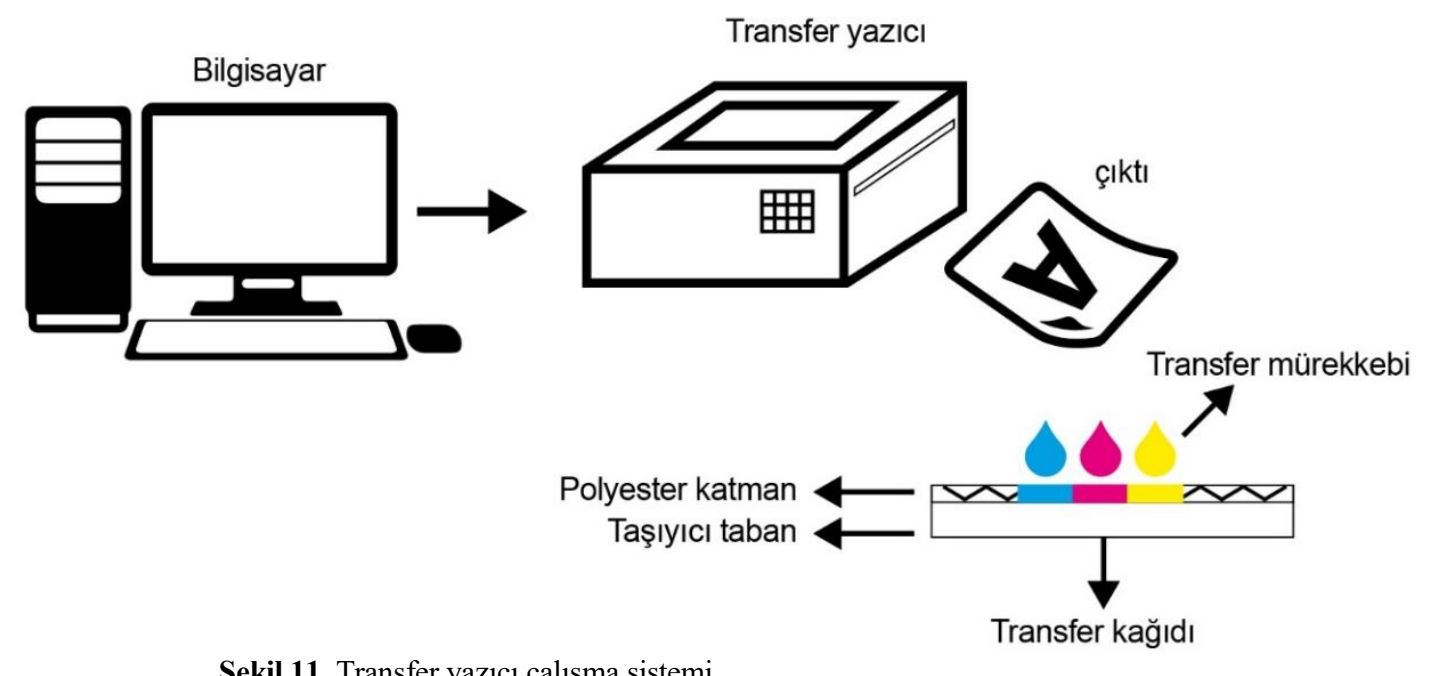

Şekil 11. Transfer yazıcı çalışma sistemi

\subsection{TRANSFER İŞLEMI}

Transfer işleminde kâğıdın üzerindeki baskılı alanlar basınçlı 1sı (termal) yöntemle yüzey yapısı transfer mürekkebini kabul edecek özelliğe sahip ürünlere transfer edilir. Transfer işlemi basınç ve sıcaklık yardımıyla olmaktadır. Ürünün özelliğine göre sıcaklık değerinin doğru ayarlanması gerekmektedir. Fazla sıcaklık değerleri özellikle tekstil ve kâğıt türevi ürünlerde (tişört, çanta, şapka, puzzle, albüm, vb.) tahribatlara neden olur. Ayrıca sıcaklık değeri kadar önemli olan bir diğer unsur ise presleme süresidir. Süre gereğinden fazla olduğunda yine tahribatlar yapması kaçınılmazdır. Manuel preslerde presleme elle yapıldığı için yeteri kadar basınç uygulanmadığında transfer mürekkebinin ürüne tüm detayları ile aktarılması mümkün olmamaktadır. Ürünlere göre transfer sıcaklık derecesi ve süreleri aşağıdaki değerlerde olması uygundur. Fakat farklı firmaların transfer mürekkepleri ve kâğıtlarına göre bu değerler değişkenlik gösterebilir. 
Tablo 1. Transfer baskı işleminde ürün türüne göre sıcaklık, zaman ve basınç değerleri (www.akrajournal.net)

\begin{tabular}{|c|l|c|c|c|}
\hline & \multicolumn{1}{|c|}{ Ürün } & Sicaklık $\left.^{\circ} \mathrm{C}\right)$ & Zaman $($ sn) & Baskı Gücü \\
\hline 1 & Kupa Bardak & 180 & 120 & Orta \\
\hline 2 & Sihirli Kupa & 180 & 120 & Orta \\
\hline 3 & Metaller & 180 & 40 & Orta \\
\hline 4 & Camlar & 180 & 360 & Orta \\
\hline 5 & Saten Kumaş & 180 & 60 & Orta \\
\hline 6 & HDF Ürünler & 180 & 90 & Güçlü \\
\hline 7 & Puzzle Mukavva & 180 & 70 & Güçlü \\
\hline 8 & Puzzle Ahşap & 180 & 90 & Güçlü \\
\hline 9 & Tişört & 180 & 100 & Orta \\
\hline 10 & Şapka & 180 & 100 & Orta \\
\hline 11 & Magnet & 180 & 60 & Orta \\
\hline
\end{tabular}

Hava kompresörleriyle eşlenik olarak çalışan pnömatik transfer preslerinde basınç, kompresörden gelen hava yardımı ile olduğu için baskının kalitesi de yüksek olmaktadır. Rotasyon presleri bobinden bobine insan eli değmeden çalışan ileri teknolojilerdir. Rotasyon preslerde, transfer kâğıdı materyalle senkronize olarak beslenerek baskı gerçekleşir. Rotasyon presler tekstil ürünlerin baskısına uygundur. Ürünün özelliğine göre metraj hızı değişkenlik gösterir.

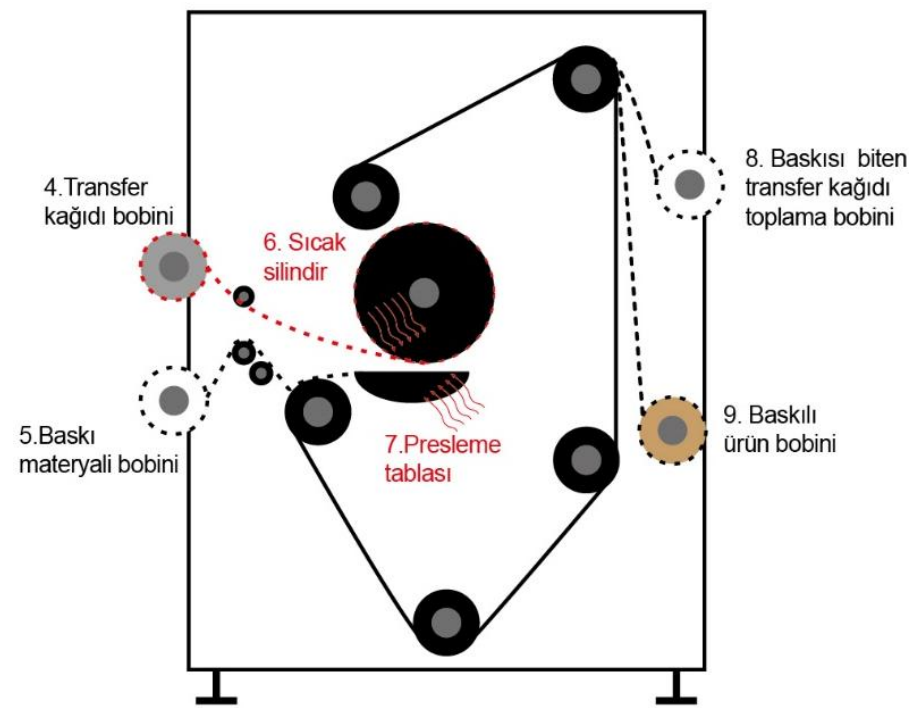

Şekil 12. Rotasyon (bobin) transfer baskı makinası çalışma sistemi (www.color-ons.net, 26.02.2018) 


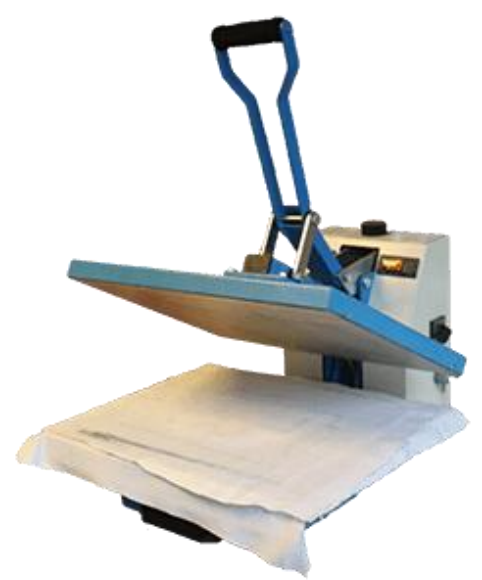

Şekil 13. Manuel transfer baskı işlemi

\subsection{BASKI SONRASI İŞLEMLER}

Transfer işleminden sonra ürün direkt kullanıma hazır olabilir ya da kesme, katlama, yapıştırma, dikme, vb. işlemlerden geçirilerek son halini alması sağlanır. Özellikle tekstil ürünleri baskı işleminden sonra konfeksiyon atölyelerinde son şeklini alırken kağıt ürünler giyotinle, metal ve plastik ürünler lazer kesim cihazları ile kesilerek son şeklini alması sağlanır.

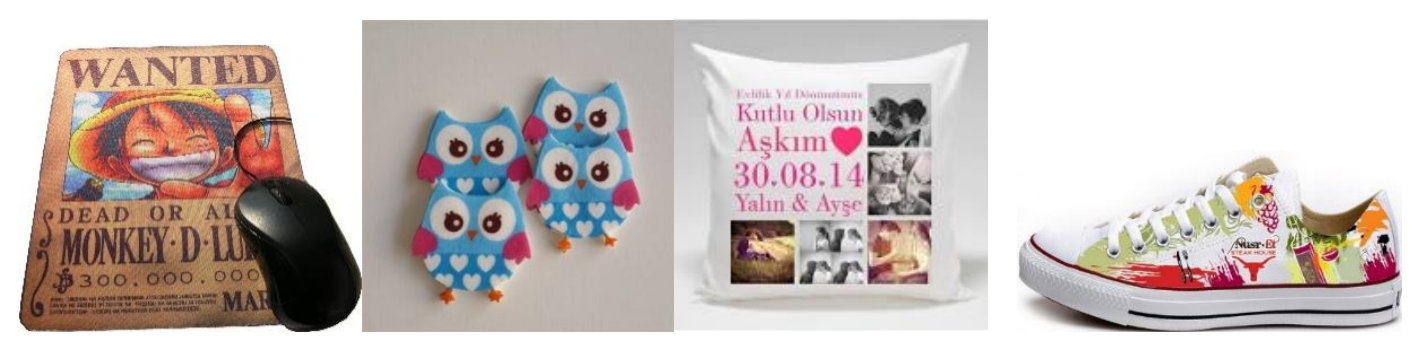

Şekil 14. Transfer baskı sonrası kaplama, kesim, dikme, vb. işlemler (www.desenlikeceler.com.tr)

\subsection{TRANSFER BASKI SONUCUNU ETKİLEYEN UNSURLAR}

\subsubsection{Baskı Hazırlık Aşaması}

Grafik tasarım işleminde kullanılacak görsellerin yüksek çözünürlükte hazırlanması gerekmektedir. Basılacak ürüne göre tram türü ve değerleri uygun seçilmelidir. Çıktı alınacak transfer yazıcıların baskı çözünürlük düzeyi baskı kalitesinde en önemli unsuru teşkil etmektedir. Transfer yazıcılarda mürekkep dolum sistemi ve mürekkep üniteleri her 6 ayda bir temizlenmelidir. Toz, kir ve diğer etki eden faktörler baskı makinesinin performansını etkiler ve mürekkebin baskı kafasına doğru akışını olumsuz yönde etkiler. Çözünürlük düzeyi düşük yazıcılarla ton geçişleri hassas görüntülerin elde edilmesi mümkün değildir. Kullanılan transfer kâğıdının kalitesi mürekkebi yüksek düzeyde tutması ve sıcak preste de en yüksek düzeyde bırakmasına göre belirlenmektedir. Ayrıca her mürekkeple her transfer kâğıdı uyum göstermemektedir. Bu nedenle mürekkep firmasının önerdiği kâğıt tercih edilmelidir. Kâğıdın materyale transferi aşamasında kâğıt tekstil yüzeyine iz bırakmamalıdır. Bu da ancak düşük gramajlı kâğıtla olmaktadır (grafikerler.org, 2018).

\subsubsection{Baskı Aşaması}

Transfer işleminde kullanılacak presin manuel ya da yarı otomatik ve tam otomatik olması baskı kalitesinde cihaz olarak etkili olduğu gibi kullanım opsiyonlarının da doğru seçimi önem taşımaktadır. Baskı sıcaklığının en ideal $190^{\circ} \mathrm{C}$ olması gerekirken $200^{\circ} \mathrm{C}$ 'de çalışılması yada sürenin 20 saniye yerine 30 saniye seçilmesi sonucu direkt etkileyecek unsurlardır. Ürünün özellikleri tam bilinmiyor ise test baskıları yaparak en ideal değerler bulunabilir. 


\subsubsection{Baskı Sonrası}

Transfer baskı tekniği dışında faaliyetler olsa da ürünün son şeklini almasında kalite düzeyini etkilemektedir. Özellikle kesim işlemlerinin basit teknolojilerle yapılması kenarlarda çapakların oluşmasına ve ürünlerin boyutlarında farklılıkların oluşmasına neden olabilmektedir.

\section{TRANSFER BASKI TEKNIĞİ EĞİTIM MÜFREDATININ OLUȘTURULMASI}

\subsection{Dersin Amacı ve Kapsamı}

Dersin amacı, transfer baskı işleminin farklı üretim aşamalarında çalışabilmek için gerekli olan teorik ve uygulamalı bilgilerin öğretilmesidir. Dersin kapsamında, transfer baskı işleminde kullanılan teknolojiler, malzemeler ve üretim işlemleri yer almaktadır. Ayrıca transfer baskı tekniğinin farklı amaçlar için kullanımına yönelik yeni fikirlere yer verilmesi faydalı olacaktır.

\subsection{Dersin İșleniş Biçiminin Olușturulması}

Transfer baskı tekniğinin tüm yönleri ile öğretilmesi için ortalama 3 kredilik Baskı Teknikleri dersi içinde en az iki hafta ayrılmalıdır. Dersin uygulama bölümünde de farklı ürünlere uygulama yaptırılması çok faydalı olacaktır. Uygulama imkânı olmayan durumlarda okulun bulunduğu bölgede transfer baskı yapan işletmelere gezilerin düzenlenmesi hem transfer baskının öğretilmesi hem de basım endüstrisi içinde farklı teknolojilerinin görülmesi açısından faydalı olacaktır.

\subsection{Transfer Baskı Tekniğinin Yer Aldığı Baskı Teknikleri Ders müfredatı}

Tablo 2. Baskı Yöntemleri Dersi Müfredatı

\begin{tabular}{|c|l|}
\hline Hafta & \multicolumn{1}{|c|}{ Konu } \\
\hline $\mathbf{1}$ & Serigrafi bask1 tekniği \\
\hline $\mathbf{2}$ & Serigrafi bask1 tekniği \\
\hline $\mathbf{3}$ & Serigrafi bask1 tekniği \\
\hline $\mathbf{4}$ & Flekso bask1 tekniği \\
\hline $\mathbf{5}$ & Flekso baskı tekniği \\
\hline $\mathbf{6}$ & Flekso bask1 tekniği \\
\hline $\mathbf{7}$ & ARA SINAV \\
\hline $\mathbf{8}$ & Tifdruk baskı tekniği \\
\hline $\mathbf{9}$ & Tifdruk bask1 tekniği \\
\hline $\mathbf{1 0}$ & Tampon baskı tekniği \\
\hline $\mathbf{1 1}$ & Dijital baskı tekniği \\
\hline $\mathbf{1 2}$ & $\begin{array}{l}\text { Transfer bask1 tekniği, teknolojileri ve malzemeleri } \\
\text { hakkında teknik bilgi (teorik eğitim) }\end{array}$ \\
\hline $\mathbf{1 3}$ & Transfer baskı işlemi (atölye uygulamalı eğitim) \\
\hline $\mathbf{1 4}$ & FìNAL SINAVI \\
\hline
\end{tabular}




\subsection{Transfer Baskı Dersinin İşleniş Çizelgesi}

Tablo 3. Transfer Baskı Atölye Uygulamalı Eğitim Müfredatı

\begin{tabular}{|c|c|}
\hline 1. & $\begin{array}{l}\text { Planlama: Her öğrenci öğretim elemanı tarafindan kararlaştırılan standart malzeme } \\
\text { üzerine nasıl bir görsel basacağının kararını vererek, atölye iş çizelgesi üzerine yazılı } \\
\text { hale getirerek yapacağı çalışmayı belirler. }\end{array}$ \\
\hline 2. & $\begin{array}{l}\text { Tasarım (basılacak görselin hazırlanması): İş çizelgesinde tanımlanan baskılı üründe } \\
\text { yer alacak tasarım, grafik programları kullanılarak her ögrencinin kendi bilgi ve } \\
\text { becerisi ile hazırlanır. }\end{array}$ \\
\hline 3. & $\begin{array}{l}\text { Transfer baskı yazıcısı ve transfer bask1 kağıdının öğrenilmesi: Transfer baskı } \\
\text { hazırlık işleminin ikinci aşamasında ögrenciler kullanılacak olan transfer kağıdını, } \\
\text { transfer mürekkepleri ve transfer yazıcı cihazı ile ilgili teknik bilgilendirme yapıllır. } \\
\text { Ayrıca kullanım aşamasında dikkat edilmesi gerekenler öğretilir. }\end{array}$ \\
\hline 4. & $\begin{array}{l}\text { Her öğrenci kendi hazırladığı tasarımı bilgisayara yükleyerek transfer yazıcıdan } \\
\text { çıktısını alır. }\end{array}$ \\
\hline 5. & $\begin{array}{l}\text { Transfer baskı presinin çalışma sistemi öğretilir. Baskı malzemesine göre farklılık } \\
\text { gösteren sıcaklık değerleri, basınç değerleri, zaman ayarları gibi değişkenler ayrıntılı } \\
\text { bir şekilde ele alınır. }\end{array}$ \\
\hline 6. & $\begin{array}{l}\text { Bask1 işlemine geçmeden, yüksek sıcaklık değerine sahip transfer bask1 presinde iş } \\
\text { sağlığı ve güvenliği açısından dikkat edilmesi gerekenler öğretilir. }\end{array}$ \\
\hline 7. & $\begin{array}{l}\text { Baskı ayarlama işlemi: Her öğrenci transfer kağıdı ile önceden temin edilen standart } \\
\text { baskı malzemesi üzerine yerleştirerek sabitleme (poza) işleminin hassas bir şekilde } \\
\text { yapılmasını öğrenir. Daha sonra baskı işlemi için gerekli olan cihaz ayarlarını } \\
\text { öğrenerek ayarlama işlemini gerçekleştirir. }\end{array}$ \\
\hline 8. & $\begin{array}{l}\text { Baskı işlemi: Basılacak malzemeye göre ideal sıcaklık, basınç ve zaman ayarlaması } \\
\text { yapılır. Her öğrenci kendi baskısını acele etmeden ve çok dikkat ederek } \\
\text { gerçekleştirir. }\end{array}$ \\
\hline 9. & $\begin{array}{l}\text { çlar tek tek kontrol edilir. Hatalı baskı sonuçlarının } \\
\text { anlıșlar ortaya konulur. }\end{array}$ \\
\hline
\end{tabular}

\subsection{Transfer Baskı Eğitiminden Hedeflenen Yetkinlikler (Çıktılar)}

- Öğrenci transfer baskıyı tanımlar.

- Transfer baskı işleminde kullanılan malzemeleri bilir.

- Transfer baskı işleminde kullanılan cihazları bilir.

- Transfer baskının nasıl gerçekleştirildiğini bilir.

- Transfer baskı tekniği ile farklı reklam ve kişisel ürünlerde kullanabileceğinin araştırmasını yapabilir ve yenilikçi fikirler geliştirir.

\section{SONUÇ}

Dünya üzerinde nitelikli iş gücü ve becerilere sahip bireyler yetiştirmek ve bu sayede ülke ekonomilerini güçlü kılmak isteyen ülkeler eğitim sistemlerini; toplumun ihtiyaçları, teknolojinin getirdiği yenilikler ve dünyayla rekabet edebilme çabaları doğrultusunda geliştirmektedirler. Meslek liselerinin ve meslek yüksekokullarının ilgili programlarında eğitim alan öğrencilerin sektörün beklentilerini karşılayan nitelikli işgücüne sahip olması hem sektörlerin büyümesinde ihtiyaç duyacakları kalifiye işgücünün temin edilmesini sağlayacak hem de daralan iş alanlarının yerine alternatif istihdam imkânı oluşturacaktır. Ayrıca kısıtlı bütçeyle bile iş kurabilme imkânın olması girişimcilik açısından firsatlar oluşturacaktır. Son yıllarda hükümetlerin öncelikli çabası, çiftçiden başlayarak ev hanımlarına kadar 
toplumun farklı kesimlerinde kendi işini kurmaya yönelik girişimciliği arttırmak olduğu bir durumda, ileriye dönük daha da büyüyecek transfer baskı sektörünün Basım ve Yayın ve matbaa eğitimi alan gençler tarafindan bilinmemesi önemli bir kayıp kabul edilmelidir. Transfer baskı tekniğini kullanan işletmelerin her geçen gün artması beraberinde transfer baskı teknolojileri, transfer malzemeleri (transfer kâğıdı ve süblimasyon mürekkebi) ve transfer baskıya uygun ürünler üreten tedarikçi işletme sayısının da artmasını sağlamaktadır. Ayrıca tamir-bakım-servis hizmetleri ile büyük bir yapı karşımıza çıkmaktadır.

Baskı Teknikleri dersinde transfer baskı tekniği ile ilgili öğrenilen teorik bilgilerin imkanlar dahilinde uygulama yaptırılarak pratik beceri kazanılması sağlanmalıdır. Uygulama çalışmasında; öğrencilerin temin edeceği ürünlere kendi tasarladıkları baskıların yaptırılması keyifli bir çalışma temposu oluşturacaktır. Bunun için her öğrenciye masaüstü yayıncılık programlarını kullanarak kendi istedikleri (kişiye özel) tasarımlar yaptırılmalıdır. Bu tasarımlar süblimasyon yazıcılarda yazdırılarak yazıcının kullanım özellikleri öğretilmelidir. Son aşamada, transfer presinde baskısını yapacağı ürün için gerekli sıcaklık ve presleme zaman ayarlarına dikkat ederek kendi baskısını yapması sağlanmalıdır. Basım ve Yayın Teknolojileri Program başkanlıkları ihtisaslaşma adına transfer baskı atölye altyapısını, müfredatlarını ve ders kaynaklarını oluşturmak koşulu ile seçmeli ders olarak programlarında yer verebilirler.

\section{KAYNAKÇA}

Denizel, M. (2011). Tekstilde transfer baskı ve tasarım ilkeleri. Yayınlanmamış Yüksek Lisans Tezi. Mimar Sinan Güzel Sanatlar Üniversitesi, Sosyal Bilimler Enstitüsü, İstanbul.

Ratte, I. (2003). Textile printing: Transfer printing. Manchester: Universty of Manchester, Institue of Science and Technology.

Storey, J. (1974). Manual of textile printing. London: Thames and Hudson.

Wells, K. (1997). Fabric dyeing \& printing. London: Octupus Limited.

2 Mart 2018 tarihinde www.akrajournal.net adresinden erişildi.

28 Şubat 2018 tarihinde www.bitmeyenkartus.com.tr adresinden erişildi.

28 Şubat 2018 tarihinde www.color-ons.net adresinden erişildi.

26 Şubat 2018 tarihinde www.grafikerler.org/forum/konu/sublimasyon-transfer-calismalarindacozunurluk.32949/ adresinden erişildi.

Nazdar'dan yeni süblimasyon mürekkepleri: Daha az mürekkep, daha yüksek baskı yoğunluğu. 27 Şubat 2018 tarihinde http://www.signgraphic.com.tr/-1-255134-nazdardan-yeni-sublimasyonmurekkepleri-daha-az-murekkep-daha-yuksek-baski-yogunlugu.html adresinden erişildi.

Tekstil üzerine süblimasyon baskılarda transfer baskı mı dispers baskı mı? 27 Şubat 2018 tarihinde http://www.signgraphic.com.tr/-1-253815-tekstil-uzerine-sublimasyon-baskilarda-transfer-baskimi-dispers-baski-mi.html adresinden erişildi.

Epson L-Series printers. 27 Şubat 2018 tarihinde http://www.winkprintersolutions.com/product/epson$\underline{1850 /}$ adresinden erişildi.

Graphics One: GO RIO PRO 5454 inç Süblimasyon Bask1 Yazıcısı, (18 Ağustos 2011). 27 Şubat 2018 tarihinde https://www.signgraphic.com.tr/-1-2211-graphics-one-go-rio-pro-54-54-inc-sublimasyonbaski-yazicisi.html adresinden erişildi.

Sublimation. 26 Şubat 2018 tarihinde http://www.vavi.pt/sublimation.html adresinden erişildi. 
Süblimasyon nedir? 27 Şubat 2018 tarihinde http://www.tekstilyazici.com/Sublimasyon_Nedir.html adresinden erişildi.

Promo Heat Professional 8 in 1 Multifunction Sublimation Heat Press Machine - Model PRO-8800X. 26 Şubat 2018 tarihinde https://www.walmart.com/ip/Promo-Heat-Professional-8-in-1Multifunction-Sublimation-Heat-Press-Machine-Model-PRO-8800X/150994526 adresinden erişildi.

38x38 Pnömatik transfer baskı presi. 26 Şubat 2018 tarihinde http://www.makinedukkani.com/38x38pnomatik-transfer-baski-presi-urun49.html adresinden erişildi.

Wermac Mod - H506. 26 Şubat 2018 tarihinde http://www.wermac.com.tr/transfer-baskimakinalari/wermac-doner-kafa-pnomatik-transfer-baski-presi adresinden erişildi.

Sublimasyon nedir? Sublimasyon baskı nasıl yapılır? 27 Şubat 2018 tarihinde http://www.serfoto.com.tr/sublimasyon-baski adresinden erişildi. 